Hindam Basith Rafiqi

PERANCANGAN FILM DOKUMENTER BATIK DRUJU SEBAGAI MEDIA PENGENALAN

BATIK KHAS MALANG

\title{
PERANCANGAN FILM DOKUMENTER BATIK DRUJU SEBAGAI MEDIA PENGENALAN BATIK KHAS MALANG
}

\author{
Hindam Basith Rafiqi \\ Penciptaan Fotografi, Pascasarjana Institut Seni Indonesia \\ Yogyakarta \\ hindambasith@gmail.com
}

\begin{abstract}
Batik druju originates from Druju Village, District of Sumbermanjing Wetan, Malang. Located in small village named Wonorejo, around the hill side of chalk-cliff in South Malang area that extending up till South Java beach. An exotic nature ambience, encouraging Batik Druju design to being the masterpiece in the world. We can find so many flora pattern, fauna pattern, sunshine pattern and a scenery pattern that inspired by the scenery around Druju village. The uniqueness of batik Druju can be found from their color, they usually use a contrast color with a line, symmetrical design and identic with solid black color. The process of creating batik design uses a drawing and stamp technique on a silk fabric. The other uniqueness that can be found on batik Druju was on their batik pattern that extend from the front area to back area. Batik Druju pattern connected because the drawing process was doing after the fabric was made into a clothes. Batik Druju also not open any branch out the area of Druju village, because they want to developing their village. The existence of Batik Druju was not really popular in the society, especially in Malang city, this reason encourage the author to design a documentary film that can explain about the origin, the pattern and the uniqueness which can be found in batik Druju.

This design was made to introduce about the origin of batik Druju, the pattern of batik Druju and it's social function to the society that lives around the area who didn't know about batik Druju. This design use a procedural design with aligning the steps that have to follow for producing the product. Based on the model's explanation, the model that was designed should divide into 3 common parts which is preproduction, production, and post-production. This design will produce a documentary film which can be an effective media to introduce about batik Druju to the society. Hopefully, with this design, the society can appreciate and accompany to preserving Indonesian traditional culture.
\end{abstract}

Key Words: Designing, Documentary film, Batik Druju

\begin{abstract}
Abstrak: Batik Druju berasal dari Desa Druju Kecamatan Sumbermanjing Wetan Kabupaten Malang. Batik Druju berlokasi di dusun terpencil bernama Wonorejo, di bawah perbukitan gunung kapur Malang Selatan yang membujur hingga pantai selatan Jawa. Suasana alam yang eksotis, mendorong karya batik Druju menjadi masterpiece di dunia. Ditemukan beragam motif flora, motif fauna, motif sinar matahari dan pemandangan alam yang terinspirasi dari alam sekitar desa Druju. Ciri khas warna batik Druju cenderung mengkombinasikan warna-warna kontras, banyak menggunakan unsur garis dan simetris, dan identik dengan warna hitam pekat. Proses penciptaan desain batik menggunakan bahan utama sutera dan dikerjakan dengan teknik tulis dan cap. Ciri khas batik Druju juga terlihat dari corak-corak batik yang menyambung dari bagian depan ke bagian belakang. Motif batik Druju menyambung karena ditorehkan setelah kain dijahit menjadi pakaian. Dan batik Druju juga tidak akan membuka di tempat lain dikarenakan ingin membesarkan sendiri desa mereka. Keberadaan batik Druju masih kurang populer di masyarakat khususnya Malang, hal ini menggugah penulis untuk merancang sebuah film dokumenter yang menjelaskan tentang asal usul, ciri khas motif hingga keunikan yang ada pada batik Druju. Perancangan ini dirancang dengan tujuan untuk mengenalkan asal usul batik Druju, ciri khas motif dan keunikan batik Druju, serta fungsi sosialnya kepada masyarakat sekitar yang belum banyak mengenal batik Druju. Perancangan ini menggunakan rancangan prosedural dengan menggariskan langkah-langkah yang harus diikuti dalam menghasilkan sebuah produk. Berdasarkan pengertian model diatas yaitu model yang dirancang harus dibuat dengan langkah-langkah dan bertahap. Tahapan tersebut terdiri dari tiga bagian yang lazim yaitu pra-produksi, produksi, dan pasca produksi. Perancangan ini menghasilkan film dokumenter yang merupakan salah satu media efektif untuk mengenalkan batik Druju kepada masyarakat. Diharapkan dengan adanya perancangan ini, masyarakat Indonesia bisa lebih menghargai dan ikut serta dalam melestarikan kesenian tradisional yang ada di Indonesia.
\end{abstract}

Kata kunci: Perancangan, Film dokumenter, Batik Druju 


\section{PENDAHULUAN}

Batik merupakan salah satu kerajinan khas Indonesia yang sudah cukup dikenal, di Indonesia sendiri terdapat beragam jenis batik yang berasal dari berbagai daerah di seluruh Indonesia. Meski Malang tidak dikenal sebagai kota batik, tapi Malang mempunyai produsen batik yang bernama Batik Druju. Batik Druju berasal dari Desa Druju Kecamatan Sumber Manjing Wetan (Sumawe).

Keunikan Motif batik Druju terletak pada motif busana yang tampak menyambung dari depan ke bagian belakang.

Keberadaan batik Druju masih kurang populer di masyarakat Malang. Sejauh ini, pengetahuan masyarakat mengenai Batik Druju khas Malang masih sangat minim, terutama di Kota Malang itu sendiri. Penyampaian informasi umumnya hanya berupa berita ataupun liputan dari media dan juga informasi dari mulut ke mulut. Namun diantaranya masih belum mampu menyampaikan informasi mengenai Batik Druju sehingga membawa audiens untuk ingin mengenal dan mengetahui lebih jauh mengenai Batik Druju.

Untuk memperkenalkan kepada masyarakat mengenai batik Druju, diperlukan sebuah media yang dapat memberikan informasi kepada masyarakat, secara riil dan lengkap, yakni sebuah dokumentasi meliputi penggambaran proses, jenis jenis dan sejarah pembuatan batik Druju sebagai kebudayaan Indonesia yang harus dilestarikan. Salah satu cara penyampaian informasi tersebut adalah dengan menggunakan media audio visual atau yang biasa disebut film.

Perancangan film dokumenter ini dimaksudkan untuk memperkenalkan sekaligus mengetahui eksistensi batik Druju sebagai produk asli kerajinan batik yang terdapat di daerah Malang. Dengan pertimbangan tersebut maka penulis memutuskan untuk melakukan studi penelitian yang akhirnya nanti dapat diwujudkan ke dalam bentuk film dokumenter mengenai batik Druju yang diharapkan dapat menyampaikan informasi secara lengkap dan informatif.

\section{DATA PERANCANGAN}

Berdasarkan data yang diperoleh di lapangan mengenai Andis Batik Druju, Pak Edi
Subagio bersama istri, Sumardiyanti yang biasa disapa Antik Subagio mendirikan usaha batik sejak 1996, Edi Subagio dibantu istrinya mulai membuat batik dengan motif dan karakteristik yang ia buat sendiri. Usaha yang dikelola mereka berdua ini memiliki banyak kendala seperti pemasaran namun masih didukung oleh kondisi alam yang bergunung kapur yang tentunya mempengaruhi proses maupun hasil pembatikan.

Motif yang dibuat merupakan inspirasi yang didapat dari bentuk yang ada di alam desa Druju itu sendiri seperti motif tumbuhan, batang, karang, dan pemandangan alam. Batik Druju mempunyai ciri khas proses pembatikan dan hasil akhirnya. Proses pembuatan Batik Druju berbeda dengan kebanyakan pembatikan lainnya yaitu dengan cara menjahit kain terlebih dahulu menjadi pakaian lalu kemudian baru di batik dan warna yang dihasilkan adalah hitam pekat. Sehingga hasil akhirnya pun memiliki motif yang menyambung di semua bagian, baik itu sisi depan badan, lengan, bahu, maupun belakang.

Tetapi dengan sangat tingginya harga dan kurang terjangkau oleh masyarakat Malang pada umumnya, membuat batik Druju ini belum banyak dikenal di kalangan masyarakat Malang sendiri. Namun dengan diterimanya batik Druju oleh para konsumennya, ibu Antik Subagio tetap semakin bersemangat dan berinovasi dalam menciptakan motif-motif batik yang baru.

\section{METODE PERANCANGAN}

Model perancangan yang dipergunakan dalam perancangan film dokumenter ini adalah model perancangan prosedural, yaitu model perancangan yang bersifat deskriptif di mana menggariskan langkah-langkah yang harus diikuti dalam menghasilkan sebuah produk. Berdasarkan pengertian model diatas yaitu model yang dirancang harus dibuat dengan langkahlangkah dan bertahap. Tahapan tersebut terdiri dari tiga bagian yang lazim disebut standart operation procedure. Ketiga bagian tersebut digambarkan dalam skema dibawah ini:

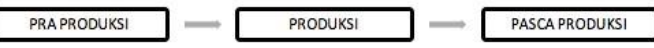

Langkah-langkah sistematis tersebut dibuat dalam bentuk skema terlebih dahulu sehingga dapat lebih mudah untuk dijadikan 
acuan dalam membuat film dokumenter. Skema ini adalah pengembangan dari model yang telah dijelaskan sebelumnya dan didasari oleh tata laksana pembuatan film dokumenter oleh Fred Wibowo.

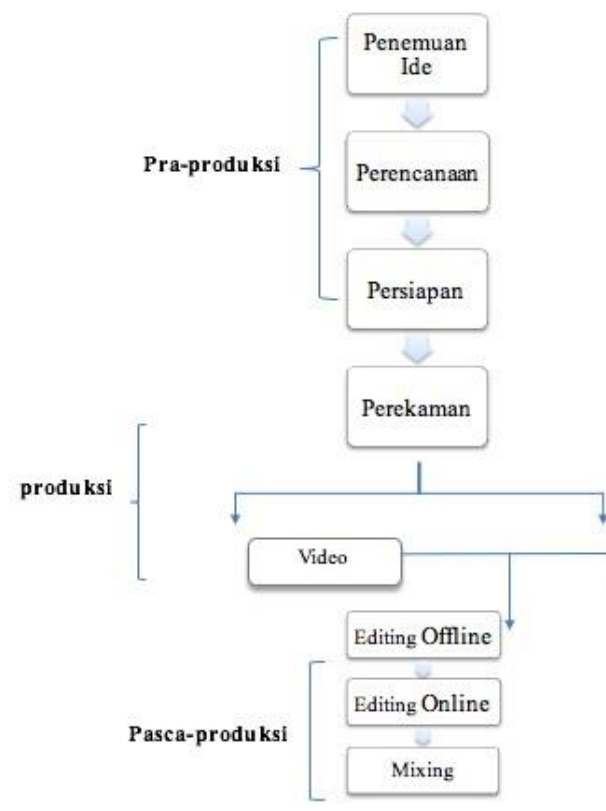

Gambar1. Skema Sistematika Perancangan Fred Wibowo

\section{SINTESIS}

Batik Druju merupakan batik tulis yang cukup berpotensi tinggi dan memiliki ragam motif yang sangat unik sehingga mudah untuk beradaptasi dengan pergeseran budaya di era globalisasi ini. Meski begitu dalam proses promosi dan pendekatannya kurang luas, sehingga banyak yang tidak mengetahui bahkan untuk warga kota Malang itu sendiri.

Mengetahui target audience yang disesuaikan dengan produk yang bersifat universal atau umum ini tentunya menjadikan media yang dipilih berdasarkan target audience nonsegmented memilih media penyiaran televisi dan online sebagai media yang dianggap dekat dengan masyarakat Indonesia. Pemilihan tersebut dipertimbangkan oleh keterbatasan waktu dan pengaksesan untuk mendapat informasi oleh target audience.

Diharapkan dengan membuat film dokumenter ini akan memudahkan target audience untuk menikmati hiburan sekaligus mendapatkan informasi berupa edukasi secara ringan dalam penyajian film ini.

\section{KONSEP PERANCANGAN}

Dengan mempertimbangkan target audience, maka untuk memperkenalkan dan mempromosikan batik Druju ini dengan media berbentuk film dokumenter yang menceritakan gambaran tentang perjalanan batik Druju di Malang, proses pembuatan batik dan serta dampak sosial kerajinan batik bagi masyarakat sekitar Malang. Film yang berdurasi 25 menit ini, dikemas secara ringkas namun mencakup semua pengetahuan umum tentang batik Druju di Malang.

Tujuan dari perancangan film dokumenter batik Druju ini adalah untuk mengenalkan dan melestarikan kebudayaan asli Malang. Film dokumenter dipilih dalam perancangan ini dengan tujuan agar masyarakat dapat tertarik dan menerima pesan film ini yaitu untuk mengenalkan dan melestarikan kerajinan batik Druju ini dengan mudah. Ilustrasi film ini akan digambarkan secara indah dengan mengemas keindahan alam desa Druju yang menginspirasi keunikan motif batik dengan tambahan sedikit cuplikan wawancara sebagai penguatan fakta, dan ditampilkan juga proses - proses membuat batik Druju itu sendiri.

\section{HASIL PERANCANGAN}

\section{Media Utama Film Dokumenter "Menera Malam"}

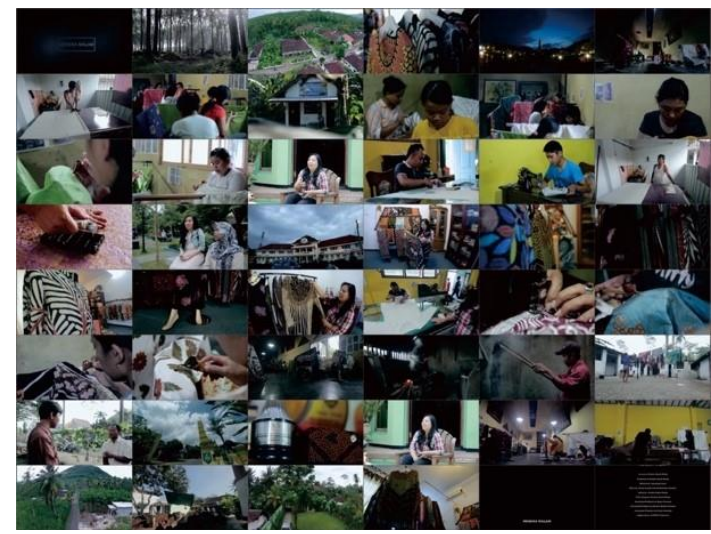

Gambar 2. Cuplikan Film Dokumenter

Media utama dalam perancangan ini 
adalah berupa film dokumenter dengan judul "Menera Malam" yang berformat DVD dengan durasi 25 menit. Proses perancangan media utama yaitu film dokumenter diawali dengan pengembangan ide dalam kegiatan pra produksi. Ide yang matang kemudian dilakukan riset atau observasi dan hasilnya nanti akan dibuat sebuah naskah produksi yang berupa storyboard. Kegiatan produksi nantinya yaitu shooting, interview, sampai audio editing akan mengacu pada storyboard tersebut sehingga kebutuhan visual bisa diambil tanpa kurang atau berlebih.

Untuk judul media film dokumenter ini adalah "Menera Malam" bahasa yang dikutip dari Kamus Besar Bahasa Indonesia, dimana arti menera adalah menera/me.ne.ra/ $\mathrm{v} 1$ memberi tera; memberi cap; memberi stempel; 2 membubuhkan tanda uji; 3 mencetak; sedangkan malam adalah bahan dasar membatik yang sangat penting berupa lilin yang digunakan untuk menutupi bagian kain agar tidak terkena pewarna saat proses pewarnaan. Dengan judul film yang sedikit unik dimaksudkan agar target audience akan semakin penasaran dan antusias untuk menonton.

Dalam film dokumenter "Menera Malam" karakter visual yang ditampilkan adalah penyampaian informasi dan faktafakta langsung dari narasumber dan hasil dokumentasi kegiatan dan bukti-bukti yang mendukung pernyataan dari narasumber tersebut sesuai dengan topik pembicaraannya. Tidak ada reka adegan dalam film ini, semua kegiatan yang direkam benar-benar terjadi.

Dalam film dokumenter ini terdapat banyak unsur estetika yang muncul karena topik yang diangkat adalah salah satu bentuk kesenian. Bentuk visualisasi kemahiran pembatik, menggambar sket dan penorehan malam, sampai keindahan alam desa Druju. Warna-warna yang terdapat film tidak banyak yang dirubah agar memperlihatkan eksotisme warnawarna yang muncul dari batik.

Penulis menggambarkan beberapa gambaran yang sesuai dengan narasi yang ada, ini dilakukan agar pemirsa dapat mencerna dengan baik apa yang disampaikan oleh narator dengan bantuan stok gambar yang ada dalam film. Dengan kualitas gambar High Definition dan didukung juga dengan drone untuk pengambilan aerial shoot diharapkan dapat lebih mencakup pengambilan gambar yang tidak monoton dan dapat mengemas tampilan visual yang lebih menarik. Selain itu, pemanfaatan insert gambar dengan teknik medium close-up hingga extreme close-up digunakan untuk memberikan kedetailan gambar dan membuat film tersebut tidak mengalami jumping gambar.

Tentu saja, diharapkan dengan penggambaran gambar pada film mampu disesuaikan dengan narasi sehingga pemirsa mampu untuk menangkap informasi dalam film ini dan mengetahui secara benar gambaran visualnya.

Proses video editing juga dilakukan dengan mengacu pada naskah produksi, sehingga semua proses mulai dari video cutting, video transition adding, video effect bisa menjadi sebuah film yang utuh sesuai naskah sampai selanjutnya dilakukan proses rendering. Namun dalam proses editing jika terdapat hasil rekaman yang kurang baik dikarenakan cuaca atau pencahayaan yang kurang, maka akan dilakukan sedikit perubahan dengan maksud memperjelas dan menyamakan dengan hasil rekaman lainnya.

\section{Media Pendukung}

Selain rancangan media utama diatas, juga akan dirancang media promosi sebagai media pendukung. Tampilan media pendukung berupa ilustrasi yang berkaitan dengan film ini dan memiliki tema visual yang sama. Ilustrasi yang digunakan dalam media pendukung ini merupakan hasil cuplikan foto dan teks. Fotografi digunakan karena akan lebih memberikan kesan dramatis dan foto juga menguatkan kesan sebuah dokumenter yang menyajikan fakta yang sesuai dengan kejadian sebenarnya. Media pendukung tersebut adalah:

\section{A. Poster Film}

Tujuan penggunaan poster adalah sebagai media komunikasi untuk menginformasikan penayangan atau screening film dokumenter berjudul "Menera Malam" ini. Poster merupakan media yang efektif untuk menyampaikan informasi lengkap dan jelas tentang film yang akan ditayangkan serta waktu dan tempat penayangannya. 


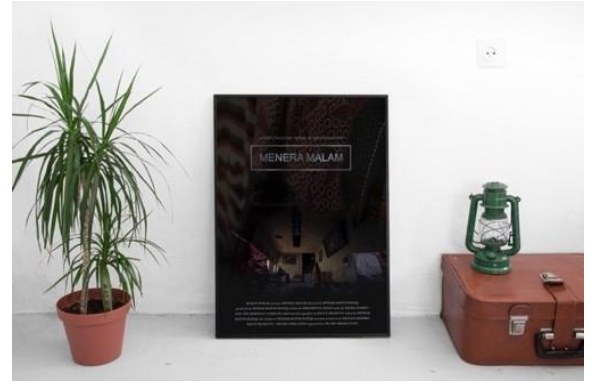

\section{B. DVD box}

Rancangan visual pada cover DVD juga hampir sama dengan media poster. Visual utama dari poster ini adalah foto suasana membatik di Andis Batik Druju dengan editing yang memberikan kesan eye catching dengan adanya fokus motif batik sebagai sampul DVD box.

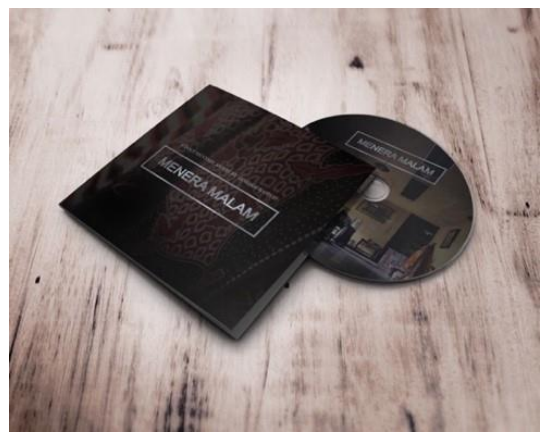

Gambar 3. DVD box

\section{X-Banner}

$\mathrm{X}$-banner merupakan media pendukung yang ditempatkan di area penayangan film atau screening. Media ini berfungsi sebagai tanda bagi orang yang sedang lewat atau mencari lokasi screening. Rancangan visual untuk media x-banner hampir sama dengan media pendukung lainnya terutama poster untuk tetap menjamin kesatuan atau unity. Ilustrasi yang digunakan merupakan ilustrasi fotografi yang sama dengan yang digunakan di dalam poster. $\mathrm{X}$-banner ini dicetak full color pada vynil ukuran $60 \times 160 \mathrm{~cm}$. Pertimbangannya adalah media ini merupakan media yang fleksibel, baik dalam penggunaannya maupun pada proses pembuatannya. X-banner ini bisa diletakkan dimana saja.

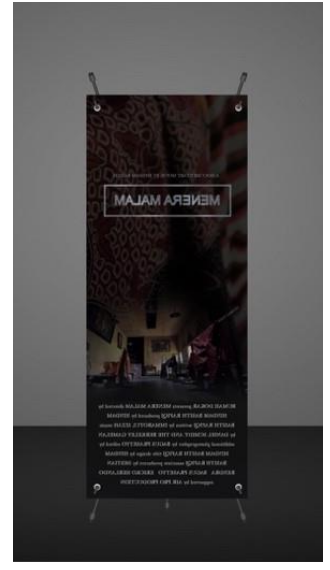

Gambar 4. X-Banner

\section{Merchandise Kaos dan Topi}

Kaos dan topi dipilih sebagai media pendukung karena memiliki beberapa fungsi yang saling mendukung. Media ini merupakan salah satu media promosi film yang bertahan lama dan ketika dipakai saat kegiatan promosi film ini akan dilihat oleh banyak orang. Media ini juga digunakan sebagai merchandise pada kegiatan pemutaran film atau screening. Kaos terbuat dari bahan katun lembut berwarna hitam yang diberi gambar cetak judul film dokumenternya menggunakan teknik sablon pada sisi depan kaos
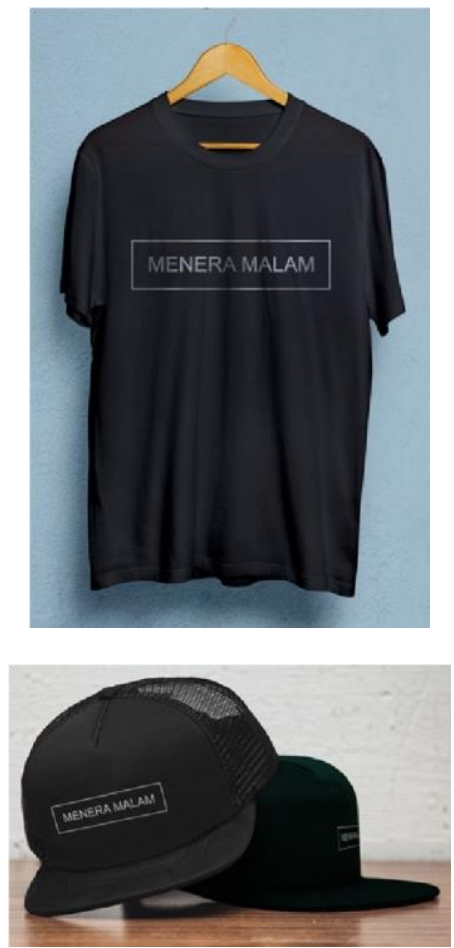

Gambar 5. Kaos dan Topi 
E. Teaser Film "Menera Malam"

Teaser film merupakan cuplikan pendek berupa iklan untuk menarik target audience untuk membuat penasaran dan ingin menonton film dokumenter yang telah dirancang ini. Tentu saja teaser yang berdurasi 01:00 ini dapat diunggah pada media sosial, hal ini dilakukan untuk memudahkan target audience mendapatkan informasi secara mudah, murah, dan seketika. Media online sosial yang dituju seperti facebook, youtube, dan instagram.

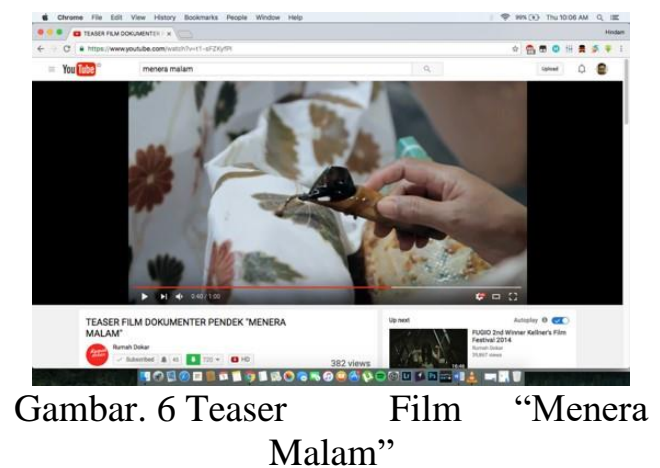

\section{KESIMPULAN}

Perancangan ini menghasilkan film dokumenter batik Druju yang dapat digunakan sebagai media pengenalan batik Druju kepada seluruh masyarakat Malang pada khususnya dan warga Indonesia pada umumnya dan diharapkan dapat lebih melestarikan lagi kerajinan batik khususnya batik Druju. Film ini merupakan sebuah bukti nyata bahwa Indonesia khusunya Malang memiliki kerajinan batik Druju yang telah diakui keberadaannya oleh UNESCO.

Diharapkan melalui film dokumenter batik ini mampu memperkenalkan budaya

Indonesia dan Malang dalam skala jangka panjang dikemudian harinya. Jika kita warga Indonesia sendiri pun tidak mampu mempertahankan dan melestarikannya, maka bukan salah mereka (Negara lain) yang menggantikan kita dalam pelestariannya, hingga dapat dengan mudah diakui sebagai milik mereka. Maka, diharapkan dengan media komunikasi berupa film dokumenter ini dapat menjadi salah satu solusi dari pemecahan masalah yang ada tersebut, sehingga kita mampu secara langsung untuk memperkenalkan, mempelajari, melestarikan dan membudayakan kerajinan asli Indonesia ini, khususnya batik itu sendiri.

\section{SARAN}

Film dokumenter dengan membawa tema kebudayaan tradisional belum banyak ditemui, padahal media seperti ini bisa menjadi pendukung pelestarian kebudayaan tradisional Indonesia. Namun perancangan sebuah film dokumenter harus dirancang dengan sistematis dan riset yang mendalam agar proses produksinya berjalan lancar dan pesan didalamnya bisa tersampaikan dengan baik. Perancangan film dokumenter ini diharapkan dapat dikembangkan lebih jauh dengan kerja sama dengan pihak-pihak yang bersangkutan agar dapat memberikan hasil yang lebih maksimal. Film dokumenter ini dapat dimanfaatkan untuk media pengenalan batik Druju dan dapat digunakan sebagai salah satu sarana pelestarian kerajinan asli Malang. Perlu dilakukan riset data dan lapangan, dimana rancangan audio dan video diperkirakan sesuai riset dari awal. Dengan demikian kita siap dalam kondisi apapun yang tidak terduga pada saat proses produksi di lapangan nantinya, hal ini dilakukan agar proses pengambilan gambar tidak membuang waktu dan mengubah jadwal yang telah ditentukan dan berakhir sia-sia.

Untuk teknik editing sendiri penulis menyarankan untuk menggunakan manual editing agar hasil terkesan natural. Karena target audience kita bisa memahami dan menikmati dengan baik informasi yang disampaikan dalam keseimbangan audio dan visual yang dikemas secara natural dalam film tersebut.

Perancangan ini juga diharapkan dapat dilanjutkan dengan tema yang lebih rinci dan mendalam ataupun mengangkat potensi kebudayaan yang lain. Tetap sesuaikan pesan utama dalam pembuatan skripsi dan film ini untuk ikut dalam serta melestarikan kerajinan asli Malang pada khususnya dan budaya Indonesia pada umumnya. Sehingga akan lebih mudah jika banyak masyarakat yang mengapresiasi karya-karya seperti ini.

\section{DAFTAR PUSTAKA}

Adiwimarta, Sri Sukesi dan Sunaryo, Adi. 1997. Kamus Besar Bahasa Indonesia.

Jakarta:Balai Pustaka 
Al-Malaky, Ekky. 2004. Komunikasi Massa Jakarta. Jakarta:Mizan

Anshori dan Kusriyanto. 2011. Keeksotisan Batik Jawa Timur. Jakarta: Elex Media Komputindo

Arikunto, Suharsimi. 1998. Prosedur Penelitian Suatu Pendekatan Praktek. Jakarta: Rineka Cipta

Ayawaila, Gerzon Ron. 2008. Dokumenter : Dari Ide sampai Produksi. Jakarta: FFTV-IKJ Press

Bungin, Burhan. 2001. Erotika Media Massa. Surakarta: UMM Press

Depdikbud. 1997. Pedoman Penyusunan Karya Tulis Ilmiah di Bidang Pendidikan, Jakarta: Balai Pustaka

Effendi, Heru. 2002. Mari Membuat Film Panduan Menjadi Produser, Jakarta: Panduan

Fachrudin, Andi. 2012. Dasar-Dasar Produksi Televisi. Jakarta: Kencana Pradana Media.

Irawanto, Budi. 1999. Film, Ideologi, dan Militer. Yogyakarta : Media Pressindo

Irawan, Candra. 1984. Batik dan Membatik. Jakarta: CV. Akadoma.

Jeffkins, Franks. 1997. Periklanan. Jakarta: Erlangga

Juniarto, Eko. 2003. Desain Produksi Dokumenter. Jakarta: IDEA International

Kudiya, Komarudin. 2011. Batik (eksistensi dan tradisi). Jakarta: Dian Rakyat

Kusrianto, Adi. 2009. Pengantar Desain Komunikasi Visual. Yogyakarta: Penerbit ANDI.

Menkominfo. 2010. Multikulturalisme, Toleransi \& National Character Building: Film Dokumenter. Jakarta: Menkominfo

Moleong, Lexy. 2002. Metodologi Penelitian Kualitatif. Bandung: Remaja Rosdakarya

Nichols, Bill. 2001. Introduction to Documentary. Indiana University Press.

Nichols, Bill. 1991. Representing Reality. Indiana: Indiana University Press.

Nugroho, Fajar. 2007. Cara Pintar Bikin Film Dokumenter. Yogyakarta: Galang Press

Prakosa. Gatot. 1997. Film Pinggiran: Antologi film pendek, Film Eksperimental, dan Film
Dokumenter. Jakarta: Nalar

Prasetyo, Anindito. 2010. Batik Karya Agung

Warisan Budaya Dunia. Yogyakarta:

Pura Pustaka

Purba, Afrillyana., Saleh, Gazalba., dan Krisnawati,

Andriana. 2005. TRIPs-WTO dan Hukum HKI Indonesia. Jakarta: PT Rineka Cipta

Sanyoto, Sadjiman Ebdi. 2006. Metode Perancangan Komunikasi Visual Perancangan. Yogyakarta: Dimensi Press.

Setyobudi, Ciptoyono. 2012. Teknologi Broadcasting. Yogyakarta: Graha Ilmu

Shanon. Weaver. 1949. The Mathematical Theory of Communication. Jakarta: Kencana Prenada Media Group

Sugiyono,. 2009. Memahami Penelitian Kualitatif. Bandung: Alfabete.

Sutrisno, Dwi Fahmi. 2013. Teknik Penyuntingan Gambar Berita Televisi (Editing). Jakarta: MNCTV

Undang-undang Penyiaran No. 32 Tahun 2002, Tentang Penyiaran.

Universitas Negeri Malang. 2010. Pedoman Penulisan Karya Ilmiah: Skripsi, Tesis, Disertasi Artikel, Majalah, laporan penelitian. Edisi kelima. Malang: Departemen Pendidikan Nasional.

Wibowo, Fred. 2007. Teknik Produksi Program Televisi. Jakarta: Pinus Book Publisher 